\title{
Management of Synchronous Locally Advanced Carcinoma Tongue and Early-Stage Carcinoma Esophagus in a Tertiary Cancer Center: A Rare Case Report
}

\begin{abstract}
Synchronous malignancy of tongue and esophagus is difficult to diagnose and treat since both the malignancies are aggressive and have poor survival. We report an unusual case study of locally advanced carcinoma tongue (Stage IVA) with early-stage carcinoma esophagus (Stage II) in a 43-year-old male for whom both the malignancies were treated with concurrent chemoradiation in a sequential manner and the patient had a complete response of both malignancies without much treatment-related morbidity and the patient is coming for follow-up with the disease-free survival of 6 months.
\end{abstract}

Keywords: Carcinoma esophagus, carcinoma tongue, early-stage, locally advanced, synchronous

\section{Introduction}

Synchronous malignancy of tongue and esophagus is difficult to diagnose and treat because both the malignancies are aggressive and have a poor survival. ${ }^{[1]}$ Sequencing of treatment is difficult as treatment of one malignancy may delay the treatment of other malignancies which may result in disease progression. Sequencing of treatment is easier if one malignancy has an indolent course and other has an aggressive nature. We report a synchronous malignancy of locally advanced carcinoma tongue with early-stage carcinoma esophagus who was treated sequentially. The patient is coming for follow-up with the disease-free survival (DFS) of 6 months (with no evidence of disease clinically and endoscopically and without treatment-related morbidity).

\section{Case Report}

A 43-year-old male with no known comorbidities, who is a smoker and alcoholic for 5 years, was evaluated for ulcero-infiltrative growth in the left lateral border of the tongue of 2 months duration. On examination, the patient's general condition was good and baseline investigations were normal. Clinical

\footnotetext{
This is an open access journal, and articles are distributed under the terms of the Creative Commons Attribution-NonCommercial-ShareAlike 4.0 License, which allows others to remix, tweak, and build upon the work non-commercially, as long as appropriate credit is given and the new creations are licensed under the identical terms.
}

For reprints contact: WKHLRPMedknow_reprints@wolterskluwer.com examination revealed an ulcero-infiltrative growth in the left lateral border of the tongue $7 \mathrm{~cm} \times 4 \mathrm{~cm} \times 1 \mathrm{~cm}$ with ankyloglossia and left Level II and Level IV cervical nodes. Wedge biopsy from the tongue was suggestive of squamous cell carcinoma Grade II. A chest X-ray showed no evidence of lung metastasis. Screening upper gastrointestinal endoscopy revealed a $1.5 \mathrm{~cm} \times 1.5 \mathrm{~cm}$ unhealthy mucosa in the middle thoracic esophagus at $31 \mathrm{~cm}$ from incisors (screening upper gastrointestinal endoscopy is one of the investigations in our hospital protocol because many of our patients are chronic smokers/tobacco chewers in whom field cancerization is common). Narrowband imaging showed unhealthy mucosa in the esophagus and biopsy of which was reported as squamous cell carcinoma Grade III. Computed tomography chest revealed thickening in the midthoracic esophagus of around $7 \mathrm{~mm}$. Hence, the patient was diagnosed as carcinoma tongue cT4aN2bM0 with early-stage carcinoma esophagus.

After a multidisciplinary board discussion, the patient was planned for chemoradiation to tongue primary and to treat esophagus sequentially since tongue malignancy was locally advanced. The patient received concurrent

How to cite this article: Nagarajan A, Sakthivelu A, Ganesharajah S. Management of synchronous locally advanced carcinoma tongue and early-stage carcinoma esophagus in a tertiary cancer center: A rare case report. Indian J Med Paediatr Oncol 2020;41:618-20.

\section{Aswin Nagarajan, Arun Sakthivelu, Selvaluxmy Ganesharajah}

Department of Radiation Oncology, Cancer Institute, Chennai, Tamil Nadu, India

Submitted: 01-Feb-2020 Revised: 27-May-2020 Accepted: 29-May-2020 Published: 29-Aug-2020

Address for correspondence: Dr. Aswin Nagarajan, Department of Radiation Oncology, Cancer Institute, Adyar, Chennai, Tamil Nadu, India.

E-mail: ashwinnagu@rediffmail. com

Access this article online Website: www.ijmpo.org DOI: 10.4103/ijmpo.ijmpo_38_20 Quick Response Code:

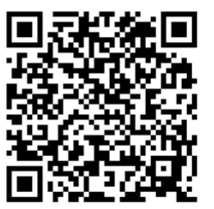




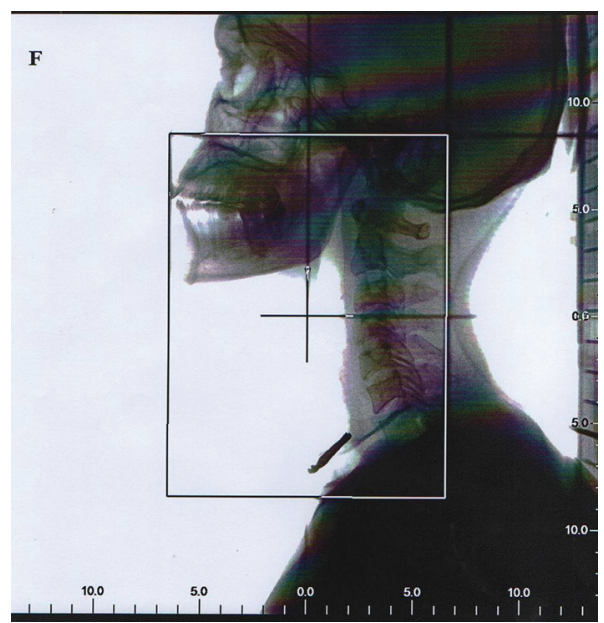

Figure 1: Simulation of tongue primary

chemoradiation [Figure 1] (66 Gy RT to primary and involved nodes using conventional technique along with 3 cycles of chemotherapy with cisplatin, 3 weekly cisplatin $100 \mathrm{mg} / \mathrm{m}^{2}$ ). The patient achieved a complete response of tongue malignancy on the first follow-up.

Follow-up upper gastrointestinal endoscopy revealed a static lesion at the midthoracic esophagus. Positron emission tomography (PET) revealed no uptake either in the esophagus or tongue. Hence, endoscopic ultrasound was done, which revealed a T2 lesion with no significant nodes. After rediscussion in tumor board, the patient was planned for definitive chemoradiation for esophagus primary because the patient was not willing for surgery. The patient received 50 Gy RT [Figure 2] using three-field techniques and 3 cycles of weekly paclitaxel $\left(50 \mathrm{mg} / \mathrm{m}^{2}\right)$ and carboplatin (AUC-2). Further chemotherapy deferred because of neutropenia requiring filgrastim support.

Upper gastrointestinal endoscopy done after 6 weeks of definitive chemoradiation revealed complete resolution of the esophageal primary. The patient is coming for follow-up with the DFS of 6 months (with no evidence of disease clinically and endoscopically).

\section{Discussion}

In synchronous malignancy, sequencing of treatment is the most important factor survival. ${ }^{[2]}$ Field cancerization theory explains the association between synchronous primary tumors in the aerodigestive tract. ${ }^{[3]}$ Three primary cancers of breast, tongue, and esophagus had been reported by Rastogi et al. ${ }^{[4]}$ The order of malignancies which occur secondary to the head and neck had been shown by Leon et al. and they showed that it had occurred predominantly in the head and neck (40\%), followed by lung (31\%) and third in the esophagus (9\%). ${ }^{[5]}$ Warren and Gates proposed criteria for defining the second primary cancer - tumors should be histologically confirmed as malignant and have to be separated from normal tissue and finally it has to be

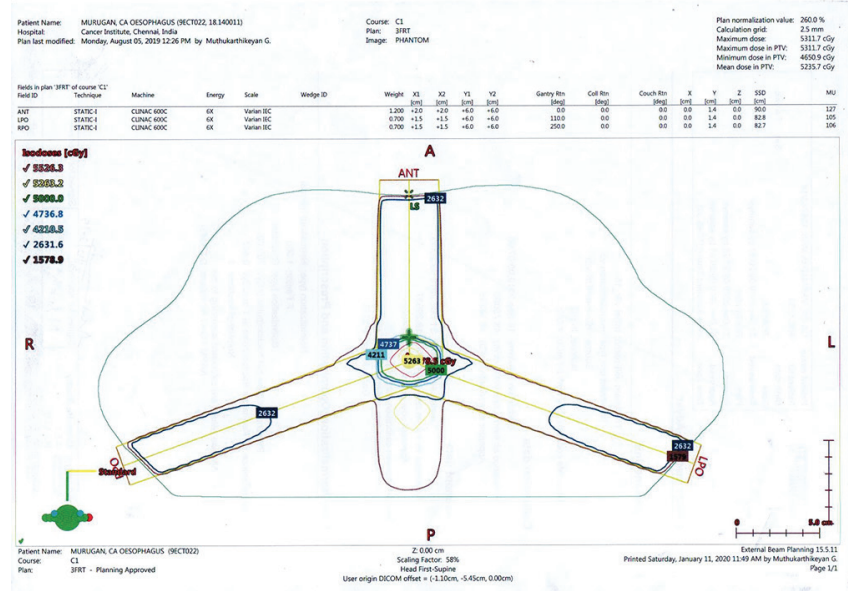

Figure 2: Three-field technique for treatment of carcinoma esophagus

differentiated from the metastases of the primary tumor. ${ }^{[6-8]}$ Our patient meets the criteria of second primary cancer as defined by Warren and Gates.

Haughey et al. conducted the meta-analysis and showed that the prevalence of a second synchronous neoplasm reported was between $0.8 \%$ and $18 \%{ }^{\left[{ }^{[9]}\right.}$ Krishnatreya et al. defined the high-risk patients in synchronous malignancies of head and neck region and upper aerodigestive tract. This study had highlighted that the habit of smoking increased the occurrence of upper aerodigestive tract cancers with a relative risk of 1.95 and showed $0.81 \%$ of all head and neck cancers developed synchronous primary in the esophagus. ${ }^{[10]}$ Hence, it is advisable to have screening endoscopy to rule out upper aerodigestive malignancies in patients with head and neck malignancies who are giving history of smoking or tobacco chewing.

In our patient, screening endoscopy during evaluation showed the second primary tumor in the esophagus. In PET, there was no uptake since the lesion was subcentimetric. Since the esophageal primary was diagnosed at an early stage compared to the tongue, it was treated after the completion of tongue primary treatment. Fortunately, the patient had a good response to chemoradiation for both the tumors.

\section{Conclusion}

Since the screening upper gastrointestinal endoscopy was done for our patient, we were able to detect esophageal cancer at an early stage, although the tongue malignancy was diagnosed at an advanced stage. The sequencing of the treatment became easy and the patient was managed appropriately. Since our patient had a good response to the chemotherapy as well as the radiotherapy, he achieved a complete response to both the primaries. This case study shows the importance of screening endoscopy in the head and neck cancers and the sequencing of the treatment if a synchronous malignancy is detected, which ultimately helps in the management and in the survival. 


\section{Declaration of patient consent}

The authors certify that they have obtained all appropriate patient consent forms. In the form the patient(s) has/have given his/her/their consent for his/her/their images and other clinical information to be reported in the journal. The patients understand that their names and initials will not be published and due efforts will be made to conceal their identity, but anonymity cannot be guaranteed.

\section{Financial support and sponsorship}

Nil.

\section{Conflicts of interest}

There are no conflicts of interest.

\section{References}

1. Nassri A, Zhu H, Muftah M, Ramzan Z. Epidemiology and Survival of Esophageal Cancer Patients in an American Cohort. Cureus 2018;10:e2507.

2. Vogt A, Schmid S, Heinimann K, Frick H, Herrmann C, Cerny T, et al. Multiple primary tumours: challenges and approaches, a review. ESMO Open 2017;2:e000172.

3. Slaughter DP, Southwick HW, Smejkal W. Field cancerization in oral stratified squamous epithelium; clinical implications of multicentric origin. Cancer 1953;6:963-8.

4. Rastogi M, Singh S, Singh S, Gupta S, Dwivedi RC. Triple primary malignant neoplasms including breast, esophagus and base tongue in an elderly male: A case report. J Cancer Res Ther 2014;10:1109-11.

5. León X, Quer M, Diez S, Orús C, López-Pousa A, Burgués J. Second neoplasm in patients with head and neck cancer. Head Neck 1999;21:204-10.

6. Choy A, Andrew Hasselt C, Chisholm E, Williams S, King W, Li A. Multiple primary cancers in Hong Kong Chinese patients with squamous cell cancer of the head or neck. Cancer 1992;70:815-20.

7. Jones AS, Morar P, Phillips DE, Field JK, Husband D, Helliwell TR. Second primary tumors in patients with head and neck squamous cell carcinoma. Cancer 1995;75:1343-53.

8. Braakhuis BJ, Brakenhoff RH, Leemans CR. Second field tumors: A new opportunity for cancer prevention? Oncologist 2005; 10:493-500.

9. Haughey BH, Gates GA, Arfken CL, Harvey J. Meta-analysis of second malignant tumors in head and neck cancer: The case for an endoscopic screening protocol. Ann Otol Rhinol Laryngol 1992;101:105-12.

10. Krishnatreya M, Rahman T, Kataki AC, Das A, Das AK, Lahkar K. Synchronous primary cancers of the head and neck region and upper aero digestive tract: Defining high-risk patients. Indian J Cancer 2013;50:322-6. 